\title{
20.
}

Journal of Rehabilitation Research

and Development Vol. 28 No. 2, 1991

Pages 1-12

\section{The initiation of gait in lower limb amputees: Some related data}

\author{
M. Nissan, PhD \\ Department of Physiology and Physical Medicine, Medical School, Technion, Israel Institute of Technology, \\ Haifa 31 096, Israel
}

\begin{abstract}
The initiation of gait, from balanced standing position to the toe-off of the stance leg, was analyzed in 8 unilateral above-knee (AK) and 10 unilateral below-knee (BK) males amputees. Thirty-one parameters were measured, including ground-foot forces and the movements and timing of hip, knee, and ankle joints. The significant changes from the normal pattern of initiation of gait found in the $\mathrm{AK}$ and $\mathrm{BK}$ amputees, as well as significant changes between the two amputees groups themselves, are described. The amputees were divided into two subgroups: those who start walking with their prosthesis and those starting with their normal leg. The two groups were compared statistically for each amputation level and all were compared to a normal subjects group. Differences relating to the choice of the swing leg were found. The findings are reported as part of a future databank.
\end{abstract}

Key words: above-knee and below-knee amputees, amputation level, gait analysis, prostheses.

\section{INTRODUCTION}

Biomechanical analyses of gait of both above-knee $(\mathrm{AK})$ and below-knee (BK) amputees have been performed by many researchers over the past years. A review by Murdoch (9) described most of the major approaches and techniques still in use and summarized most of the known data. Recent studies have added further information, some aiming at improving prosthetic design and manufacturing

Address all correspondence and requests for reprints to: $M$. Nissan, PhD, Depart ment of Physiology (Pulmonary Physiology Unit), Rappaport Family Institute for Research in the Medical Sciences, POB 9697, Haifa 31 096, Israel.
(3), others aimed at improving the theoretical analysis (10), and some which attempted to use biomechanics criteria to better fit prostheses (13). Gage and Hicks (5) reviewed the current use of gait analysis in all aspects of prosthetics.

The majority of investigators concentrate their efforts on level walking, which is the steady state, semiautomatic period of walking. Their work led to the development and improvement of a number of highly successful prostheses and auxiliary mechanisms, some of which were described by Murdoch (9). However, biomechanical techniques did not become a standard diagnostic and assessment tool at the clinical and workshop level. There is still an urgent need to identify simple and easily measurable parameters that are significantly affected by various pathologies or misalignments, and the search goes on (15).

So far, the use of gait analysis in the prosthetic workshop and the orthopedic clinic has been limited. One of the major reasons for this situation is the almost exclusive use of level walking data as being representative of gait. It has been shown that similar level-walking kinetics will be achieved with a number of different combinations of active muscles and nerves (11). Many pathologies, prosthetic misalignments, or discomforts might be compensated for, hidden, and/or missed in level-walking gait analysis. The use of electromyography (EMG) at the workshop or clinic, using surface electrodes, is not common and does not offer a real solution, being mostly qualitative and limited in nature (11), while in most cases the use of needle electrodes is not practical outside the hospital and the laboratory.

Investigating gait periods other than level walking might lead to a better understanding and assessment of 
pathologic gait. A number of publications have dealt with special periods or events in gait. A recent publication of this kind (14), analyzes the biomechanics of reactions to impending falls. For safety reasons, this approach cannot be used in the practical situation, but should lead to a better understanding of the locomotor system. Similar approaches can be found in Dickstein et al. (4) and Vittas et al. (17), both of whom look at standing patterns as an indication for disability.

A handful of researchers have looked into the initiation of gait, the subject of our present work, in the normal, healthy subject $(1,2,6,8,12)$. These studies lead to a better understanding of this important period in gait and create a normal database for future work.

Very few researchers have examined the biomechanics of gait in the amputee performing other than level walking. One such work is by Summers, et al. (16), who investigated foot loading during standing. Another is the work published by Vittas, et al. (17), who reviewed body sway in BK amputees as a means for assessment of stability.

The purpose of the present study is twofold: first, to start the creation of a database needed for future work concerning the important period of the initiation of gait; and, second, to identify a set of parameters to be used in the clinic and the workshop. We believe that in order for these parameters to be useful in the non-laboratory environment they have to be simple, fast, and inexpensive to measure, as well as easy to interpret, noncontroversial in nature, and causing minimal interference or disturbance to the patient. Following our first paper, in which we described the basic techniques and methods in detail and reported the results from normal male and female subjects (12), the present report introduces the results from $\mathrm{AK}$ and $\mathrm{BK}$ amputees using an identical approach.

\section{MATERIALS AND METHODS}

The initiation of gait (IG) was defined as the time interval between a visual start signal (S) and the toe-off (TO2) of the second foot to leave the floor, defined as the stance leg. Two Kistler force platforms (Kistler Instruments AG) and a Vicon system (Oxford Metrics Ltd., using four TV cameras on-line with a PDP $11 / 23$ computer) recorded the patient's three-dimensional ground-foot forces and lower limb movements, as described in detail by Kirtley, et al. (7). A green light served as a start signal. The PDP $11 / 23$ computer was used for data collection and analysis. The patient started the test standing erect, each foot on one force platform. When given a signal, the patient started walking forwards at his own comfortable speed. The swing leg was chosen instinctively by the subject in every test without comments or instructions. All the equipment, methods, and definitions used in this work were identical to those used and described in our previous publication (12).

Ten BK amputees (weighing $788 \mathrm{~N}$ on average), eight $\mathrm{AK}$ amputees (weighing $738 \mathrm{~N}$ on average), and seven normal subjects (weighing $736 \mathrm{~N}$ on average), all males, were tested (see Table 1). Four tests were recorded for each patient and the last three were evaluated. Thirty-one parameters were measured and analyzed for each run. These parameters, chosen for their relative simplicity and ease of measurement, included the average forces between the start signal (S) and the time of the first measurable reaction $(\mathrm{R})$, the maximal and minimal values of all forces and angular movements in the sagittal plane during the first stride (up to TO2), and the loading and unloading periods of the vertical force between the ground and the feet. Other parameters, such as impulses at various times, moments around the joints, etc., will be the subject of further research. Full details and nomenclature are given in the appendix. The parameters were compared statistically between the various groups, using the nonparametric Wilcoxon rank test.

\section{RESULTS}

The results will be presented in two parts: first, the AK amputees, followed by the BK amputees.

Table 1.

Patients and subjects.

\begin{tabular}{rlccc}
\hline Group & Description & n & Age(SD) & Tests \\
\hline A & normal subjects & 7 & $44(13)$ & 28 \\
AK & above-knee amputees & & & \\
B & swing leg = prosthesis & 3 & - & 12 \\
C & swing leg = normal leg & 5 & - & 20 \\
& Total & 8 & $45(15)$ & 32 \\
BK & below-knee amputees & & & \\
D & swing leg = prosthesis & 5 & - & 20 \\
E & swing leg = normal leg & 5 & - & 20 \\
& Total & 10 & $53(15)$ & 40 \\
\hline
\end{tabular}

All males, wearing their own, low heel or flat shoes; none using any walking aids. $\mathrm{SD}=$ standard deviation 


\section{AK Amputees}

A total of 24 tests of AK amputees were analyzed. Three patients systematically used their prosthetic leg as the swing leg to leave the ground first (group B), while the other five used their sound leg as the swing leg (group C).

Twenty-one tests of normal subjects were analyzed for comparison (group A). Results from typical AK amputees, starting with either leg, and a typical normal subject are given in Figures 1, 2, 3, 4, 5, and $\mathbf{6}$. The detailed results for all the $\mathrm{AK}$ amputees, groups $\mathrm{B}$ and $\mathrm{C}$, are given in Table 2, while a similar list for the normal group, A, appears in Table 2a and Table $\mathbf{2 b}$ of Nissan and Whittle (12).

The parameters which were found significantly different from normal in all AK amputees are described in Table 3 and Table 4. They include smaller peak forces between the stance legs and the ground in all three dimensions, faster unloading of prosthetic stance leg, smaller knee flexion in the stance leg during the whole stride, and diminished ankle flexion. The midswing knee flexion is completely

Table 2a.

Summary of results for above-knee (AK) amputees: forces.

\begin{tabular}{|c|c|c|c|c|c|c|c|c|c|c|c|c|c|c|c|c|c|}
\hline \multirow{2}{*}{$\begin{array}{l}\text { Pt. } \\
\text { Code }\end{array}$} & \multirow{2}{*}{$\begin{array}{c}\text { Amp } \\
\text { type leg }\end{array}$} & \multirow{2}{*}{$\begin{array}{c}\mathbf{B w} \\
\mathbf{N}\end{array}$} & \multirow{2}{*}{$\begin{array}{c}\text { Swing } \\
\text { leg }\end{array}$} & \multirow{2}{*}{$\begin{array}{l}\text { T1 } \\
\mathrm{ms}\end{array}$} & \multirow{2}{*}{$\begin{array}{l}\mathrm{T} 2 \\
\mathrm{~ms}\end{array}$} & \multicolumn{3}{|c|}{$\mathbf{F x}$} & \multicolumn{4}{|c|}{ Fy } & \multicolumn{5}{|c|}{$\mathbf{F z}$} \\
\hline & & & & & & $\begin{array}{l}\text { Max1 } \\
\text { \%BW }\end{array}$ & $\begin{array}{l}\text { Max2 } \\
\% B W\end{array}$ & $\begin{array}{l}\text { Max4 } \\
\% B W\end{array}$ & $\begin{array}{c}\text { Av1 } \\
\text { \%BW }\end{array}$ & $\begin{array}{l}\text { Max1 } \\
\text { \%BW }\end{array}$ & $\begin{array}{l}\text { Max2 } \\
\% \mathrm{BW}\end{array}$ & $\begin{array}{l}\text { Max4 } \\
\% B W\end{array}$ & $\begin{array}{c}\text { Av1 } \\
\text { \% BW }\end{array}$ & $\begin{array}{l}\text { Max1 } \\
\% \mathrm{BW}\end{array}$ & $\begin{array}{l}\text { Max2 } \\
\% B W\end{array}$ & $\underset{\% B W}{\operatorname{Min}}$ & $\begin{array}{l}\text { Max3 } \\
\% B W\end{array}$ \\
\hline IA7 & AK-R & 750 & $\mathrm{~L}$ & 720 & 1350 & 6 & 7 & 13 & 5 & 6 & 8 & 10 & 57 & 81 & 99 & 92 & 96 \\
\hline IB3 & AK-L & 900 & L & 410 & 1200 & -3 & 9 & 22 & 3 & 4 & 4 & 7 & 24 & 38 & 96 & 92 & 109 \\
\hline IB4 & AK-L & 640 & $\mathrm{R}$ & 890 & 1700 & 6 & 5 & 10 & 2 & 5 & 7 & 8 & 58 & 71 & 105 & 94 & 102 \\
\hline IB8 & AK-R & 690 & $\mathbf{R}$ & 700 & 1750 & -2 & 6 & 22 & 4 & 8 & 3 & 8 & 38 & 56 & 101 & 92 & 98 \\
\hline ICl & AK-R & 680 & L & 830 & 1560 & 4 & 6 & 11 & 2 & -6 & 10 & 11 & 65 & 82 & 100 & 91 & 101 \\
\hline IC5 & AK-L & 660 & $R$ & 840 & 1540 & 8 & 4 & 12 & 4 & 6 & 6 & 5 & 52 & 72 & 102 & 92 & 98 \\
\hline IC7 & AK-L & 700 & L & 460 & 1250 & 0 & 9 & 19 & 4 & 8 & 5 & 9 & 43 & 74 & 93 & 90 & 105 \\
\hline IG3 & AK-R & 880 & L & 700 & 1240 & 12 & 15 & 20 & 3 & 6 & 8 & 9 & 53 & 74 & 102 & 82 & 104 \\
\hline Total & AK: & 738 & - & 690 & 1450 & 4 & 8 & 16 & 3 & 5 & 6 & 8 & 49 & 69 & 100 & 91 & 102 \\
\hline & SD: & 93 & - & 160 & 200 & 5 & 3 & 5 & 1 & 4 & 2 & 2 & 12 & 14 & 4 & 3 & 4 \\
\hline
\end{tabular}

Directions of forces on the legs:

$\mathrm{Fx}=$ positive forward

$\mathrm{Fy}=$ positive medially

$\mathrm{Fz}=$ positive upwards

Table 2b.

Summary of results for above-knee (AK) amputees: Joint movement.

\begin{tabular}{|c|c|c|c|c|c|c|c|c|c|c|c|c|c|c|c|}
\hline \multirow{2}{*}{$\begin{array}{l}\text { Pt. } \\
\text { Code }\end{array}$} & \multirow{2}{*}{$\begin{array}{c}\text { Amp } \\
\text { type leg }\end{array}$} & \multirow{2}{*}{$\begin{array}{c}\text { Bw } \\
\mathbf{N}\end{array}$} & \multirow{2}{*}{$\begin{array}{c}\text { Age } \\
y\end{array}$} & \multirow{2}{*}{$\begin{array}{c}\text { Swing } \\
\text { leg }\end{array}$} & \multicolumn{4}{|c|}{ H } & \multicolumn{3}{|c|}{$\mathbf{K}$} & \multicolumn{4}{|c|}{ A } \\
\hline & & & & & $\begin{array}{c}\text { Max1 } \\
\text { deg. }\end{array}$ & $\begin{array}{c}\text { Max2 } \\
\text { deg. }\end{array}$ & $\begin{array}{c}\text { Max3 } \\
\text { deg. }\end{array}$ & $\begin{array}{c}\text { Max4 } \\
\text { deg. }\end{array}$ & $\begin{array}{c}\text { Max1 } \\
\text { deg. }\end{array}$ & $\begin{array}{c}\operatorname{Max} 2 \\
\text { deg. }\end{array}$ & $\begin{array}{c}\text { Max3 } \\
\text { deg. }\end{array}$ & $\begin{array}{c}\text { Max1 } \\
\text { deg. }\end{array}$ & $\begin{array}{c}\operatorname{Max} 2 \\
\text { deg. }\end{array}$ & $\begin{array}{c}\text { Max3 } \\
\text { deg. }\end{array}$ & $\begin{array}{c}\text { Max4 } \\
\text { deg. }\end{array}$ \\
\hline IA7 & AK-R & 750 & 41 & $\mathrm{~L}$ & -2 & -3 & 20 & 6 & -2 & 3 & 35 & 1 & 3 & 8 & -8 \\
\hline IB3 & AK-L & 900 & 41 & $\mathrm{~L}$ & -2 & 6 & 10 & 0 & 0 & 3 & 30 & 0 & 4 & 2 & -7 \\
\hline IB4 & AK-L & 640 & 64 & $\mathrm{R}$ & 4 & -3 & 25 & 2 & 0 & 0 & 38 & - & 0 & 18 & -4 \\
\hline IB8 & AK-R & 690 & 26 & $\mathrm{R}$ & -14 & - & 30 & 8 & 0 & 15 & 56 & 3 & 8 & 9 & -10 \\
\hline $\mathrm{ICl}$ & AK-R & 680 & 58 & $\mathrm{~L}$ & -9 & -2 & 30 & 18 & -3 & 0 & 38 & 3 & 3 & 16 & -8 \\
\hline IC5 & AK-L & 660 & 29 & $\mathrm{R}$ & 4 & -6 & 29 & 30 & 6 & 0 & 50 & 9 & 4 & 8 & -8 \\
\hline IC7 & AK-L & 700 & 66 & $\mathrm{~L}$ & -10 & 5 & 32 & 12 & -1 & 10 & 25 & 0 & 6 & -2 & -6 \\
\hline IG3 & AK-R & 880 & 35 & $\mathrm{~L}$ & 8 & - & 33 & 15 & -5 & 0 & 50 & 10 & 2 & 5 & -10 \\
\hline \multirow[t]{2}{*}{ Total } & AK: & 738 & 45 & - & - & - & 26 & 11 & - & 4 & 40 & 4 & 4 & 8 & -8 \\
\hline & SD: & 93 & 15 & - & - & - & 7 & 9 & - & 6 & 10 & 4 & 3 & 6 & 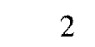 \\
\hline
\end{tabular}

Directions of angular movement:

$\mathrm{H}$ and $\mathrm{K}$ are positive in flexion; $\mathrm{A}$ is positive in dorsiflexion. 


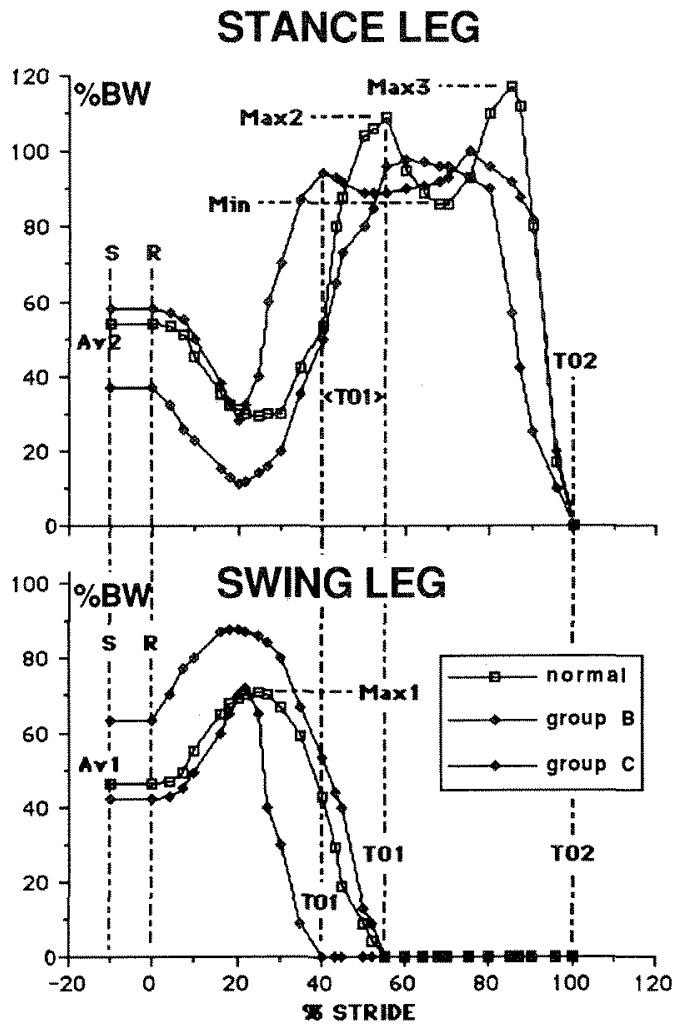

Figure 1.

The vertical force $(\mathrm{Fz})$ in $\mathrm{AK}$ amputees and normal subjects.

missing in the prosthetic leg. As one would expect, the prosthetic swing ankle is locked.

The statistical significance of the differences between groups A, B, and C are given in Table 4. A number of highly significant differences between all $\mathrm{AK}$ amputees (groups B and C) and normal subjects (group A) were identified: the fore-aft forces on both legs are much smaller in amputees, compared with normal subjects, and the first peak vertical forces are smaller in the stance legs of amputees in both groups.

The findings related to sub-groups within the $\mathrm{AK}$ amputees are of limited value because of the small group sizes. Comparing the AK amputees who used their sound leg as the swing leg (group C) to normal subjects, the only highly significant differences were found in the premovement vertical forces (Fz-Av1 and Fz-Av2). The sound swing leg carried much more than half the body weight, thereby reducing the load on the prosthesis. Nonsignificant differences $(\mathrm{p}<0.05)$ were found in other parameters, such as T, Fx-Max1, Fy-Max2, and K-Max2.

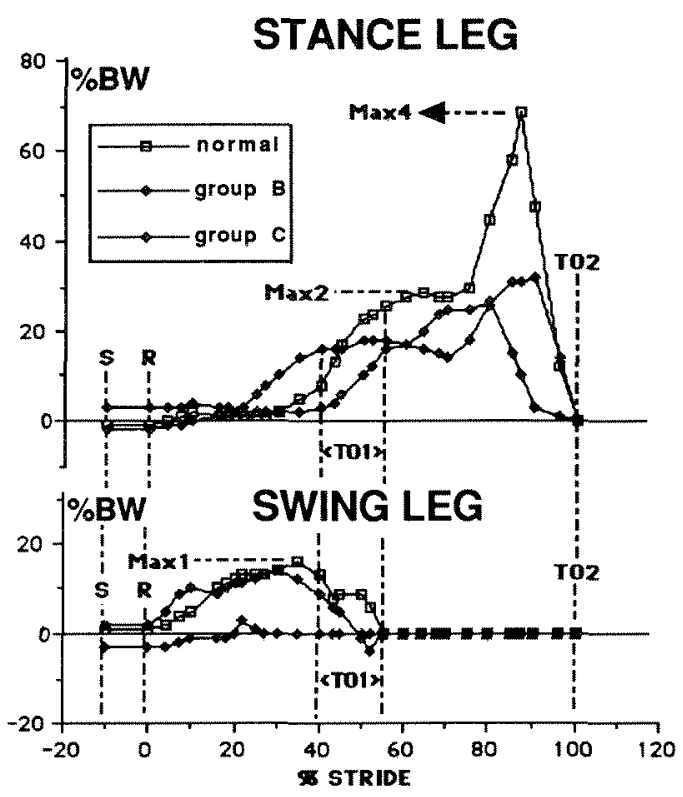

Figure 2.

The fore-aft force (Fx) in AK amputees and normal subjects.

\section{BK Amputees}

Thirty tests with $10 \mathrm{BK}$ amputees were analyzed. The amputees' personal data are summarized in Table 1. Five patients (15 tests) used the prosthetic leg as their swing leg (group D); the other five used their intact leg as the swing leg (group E). The findings are compared to the normal group A (21 tests) and the two AK amputee groups B and C (24 tests), described previously. Results from typical BK amputees, starting with either leg, and from a typical normal subject are given in Figures 7, 8, 9, 10, 11, and 12 . The results from all BK amputees are presented in Table $\mathbf{5 a}$ and Table $\mathbf{5 b}$.

Both BK amputee groups D and $\mathrm{E}$ are different from the normal A group in a number of parameters: all groundfoot forces are smaller in the amputee (see Table 6). The loading (T1) and unloading (T2) of the amputee's stance leg are shorter than normal. The hips and knees flex to a lesser degree in both legs in BK amputees; the hip hyperextending in the stance legs. The stance leg ankle flexes less towards toe-off. The most significant statistical differences between normal subjects and the BK amputees, the two BK groups themselves, and between BK and AK amputees, are calculated using the Wilcoxon rank-sum test, and are given in Table 7. 


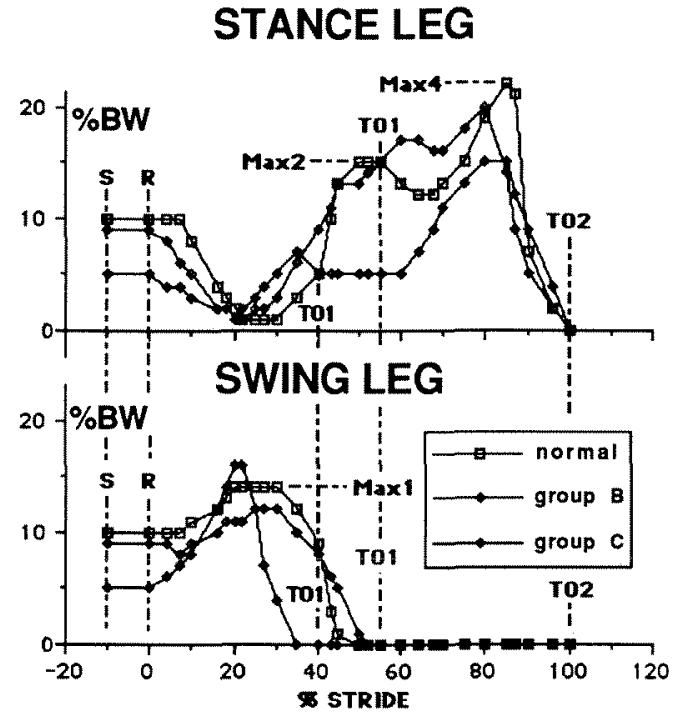

Figure 3.

The mediolateral force (Fy) in $\mathrm{AK}$ amputees and normal subjects.

\section{DISCUSSION}

The results presented in this work seem to be the first concerning the initiation of gait in amputees. The majority of the existing literature and published data deal with standing still or level walking. The assessments of the clinician and prosthetist are based mostly on those two steady-state situations, as described in the introduction. The initiation of gait (IG), occurring whenever there is gait, is too short (total of less than $1 \mathrm{sec}$ ) and complex to be analyzed visually, and so far has been ignored. IG is a most interesting period of gait, during which a large portion of the neuromuscular system is necessarily in operation, in contrast with the steady-state level walking, during which only some of the muscles (and the related nerves) have to actively participate (11). It is assumed that pathologies or misalignments which affect level walking in insignificant ways will alter the patterns of forces and movements during the initiation of gait to a much larger extent, thereby enabling a more accurate diagnosis. These changes during IG are expected to occur in the forces, moments, angular and linear movements, and EMG, as well as various combinations of these factors. Some of these parameters are difficult to measure or calculate outside the laboratory or the hospital, while others can be measured using minimal

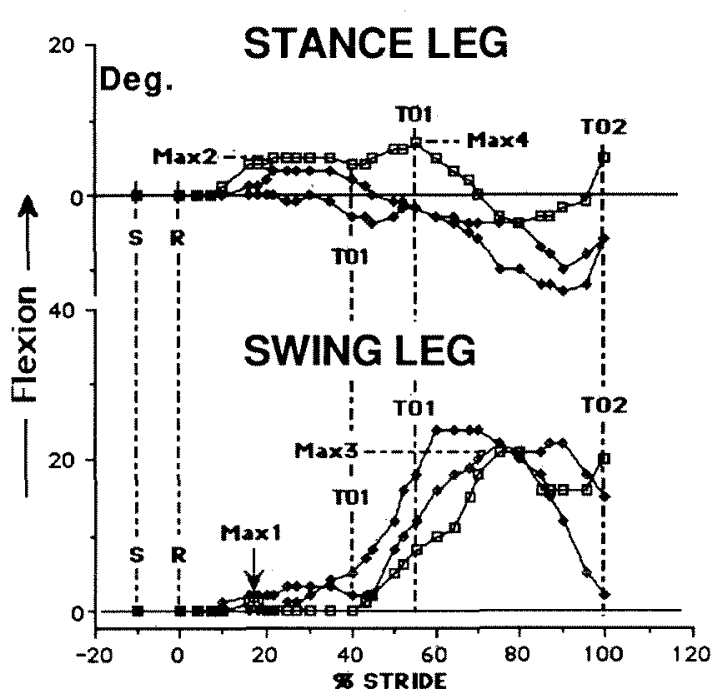

Figure 4.

Flexion-extension of the hips $(\mathrm{H})$ in $\mathrm{AK}$ amputees and normal subjects.

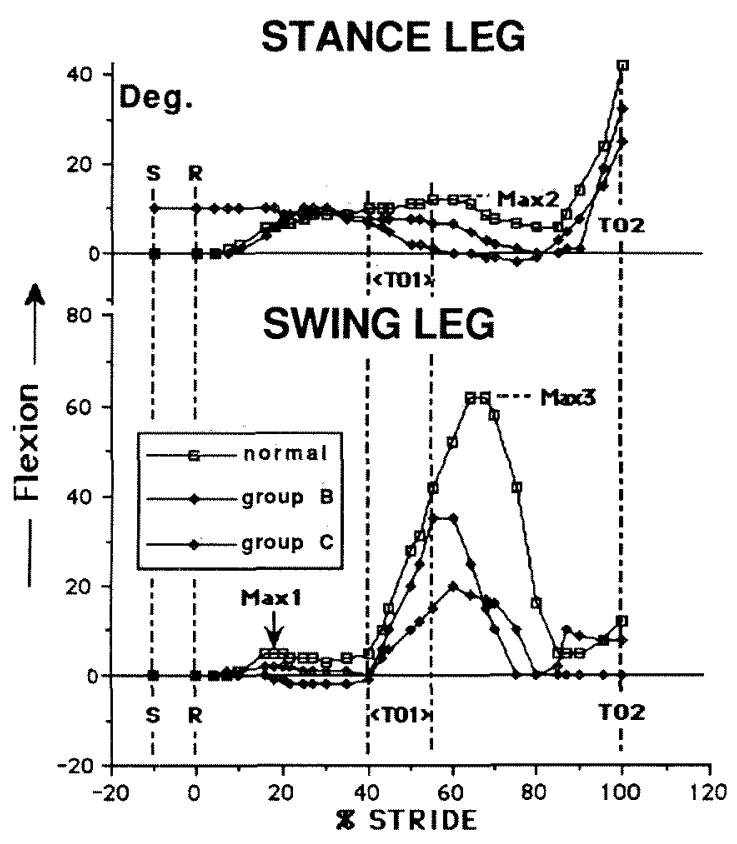

Figure 5 .

Flexion-extension of the knees $(\mathrm{K})$ in $\mathrm{AK}$ amputees and normal subjects. 
equipment in outpatient or workshop conditions by technicians or paramedical personnel. Our research tested the hypothesis that some of the parameters from the second group (i.e., those that are simpler and easier to measure) can be used as indicators of the quality of fitting and the performance of amputees.

The Kistler force platforms can record and analyze data at $500 \mathrm{~Hz}$, but our previous work indicated that a sampling rate of $50 \mathrm{~Hz}$ is adequate. The possible spatial errors in the system were described in detail by Whittle (18), who concluded that the combined system, used later in the commercial Vicon system, was "rapid, reliable and easy to use."

AK amputees were found to be significantly different from normal subjects in a number of parameters described above, and in Table 3 and Table 4. Most amputees apparently preferred to unload their prosthesis during the R-S period and to use their sound leg as the swing leg (group C) later on. Slower forward motion resulted from smaller fore-aft forces, causing smaller vertical forces in both legs, especially a smaller peak Fz-Max2, and smaller knee and ankle flexion, compared to normal subjects. The prosthetic stance legs were unloaded significantly faster than in normals. The prosthetic ankle flexed significantly less than the normal ankle in all groups of amputees and in all periods of IG, as expected.

The number of highly significant differences between BK amputees and normal subjects is smaller than the

Table 3.

Summary of major AK amputees' changes from normal, related to gait timing (upper row).

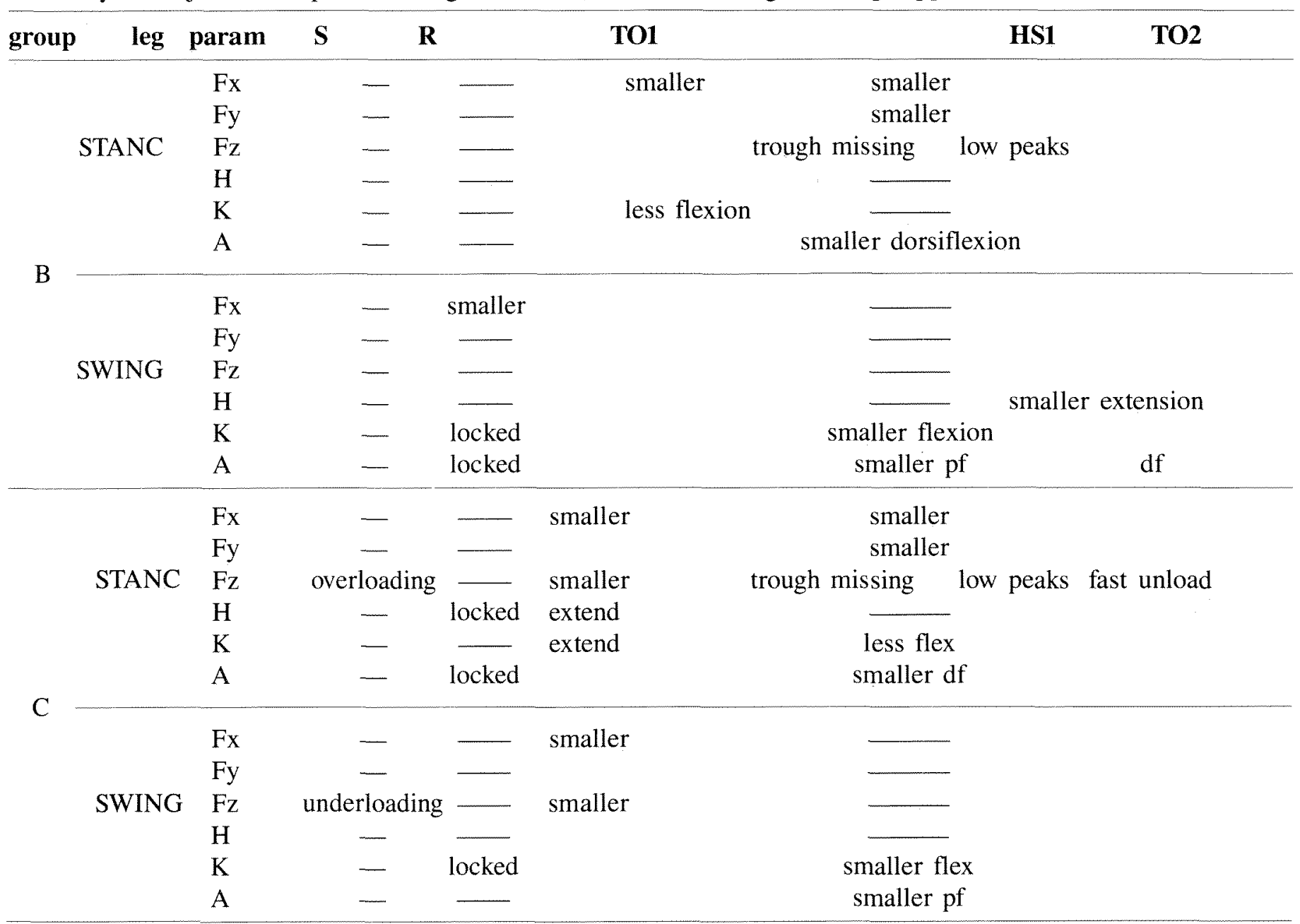

Group B: prosthesis used as swing leg

Group $C$ : prosthesis used as stance leg

$\mathrm{pf}=$ plantarflexion; flex $=$ flexion $;$ ext $=$ extension 


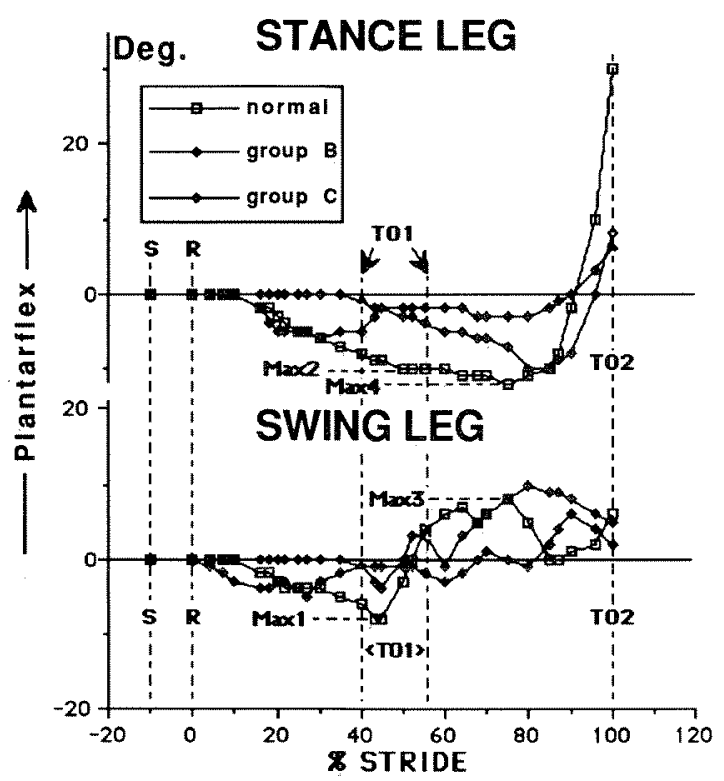

Figure 6.

Dorsiplantar flexion of the ankles (A) in AK amputees and normal subjects.

number found between $\mathrm{AK}$ amputees and normals. This result is expected, considering the lesser disability of the BK amputees. The fore-aft forces, the first peak vertical forces at midstance, and the peak plantarflexion in the stance ankles were smaller $(\mathrm{p}<0.001)$ in the BK amputee, in comparison to the normal subject. The slower pace of unloading the stance leg $(p<0.01)$ in amputees, together with the previous results, indicate a tendency for slower and more careful gait. The much smaller BK's second midstance peak vertical force (Fz-Max3) in the sound stance leg (group $\mathrm{D}, \mathrm{p}<0.001$ ) is another indication of the same tendency.

Comparison between $\mathrm{AK}$ and $\mathrm{BK}$ amputees using their prosthesis as the swing leg (groups $B$ and $D$ ) result in some differences at the $p<0.05$ level, mainly because of the small sample size. The same results were found between the amputee subgroups $\mathrm{C}$ and $\mathrm{E}$, who used their normal legs as the swing leg (see Table 7).

Comparing the two BK amputees subgroups in Table 7 , one finds the normal midstance knee flexion (K-Max2) missing, or even replaced by hyperextension in group $\mathrm{E}$. This easily measurable parameter might be linked directly with major gait deviations and consequently be used by the prosthetist as an indicator for quality of fit. Another difference is the smaller active push-off plantarflexion in the prosthetic stance leg ankles (group E), as can be expected from present day passive prosthetic ankles.

One of the aims of prosthetic fitting is to restore as much of the normal patterns of movement as possible. Our findings, so far, support the hypothesis that some relatively easily measurable parameters in amputees are significantly different from normal subjects during IG. We further assume, and this has yet to be tested, that approaching normal values by changing the prosthetic alignment or components will be followed by improvement in amputee gait.

The correlation between the various parameters measured in the present work (and probably some others to be defined and measured in the future), still needs to be tested. However, we believe that the parameters are interrelated. An improvement in one of the parameters that distinguishes between normals and $\mathrm{BK}$ or $\mathrm{AK}$ amputeesbringing it nearer the normal value-will indicate a pattern of walking that is nearer the normal and will lead to improvement in the other parameters as well. Further studies are planned, designed to test our last hypothesis. Once proven, this would mean that measurement of very few parameters, possibly even a single force component or angle, will enable an immediate objective assessment of prosthetic fit and alignment. In this case, the equipment

Table 4.

Statistically significant differences between groups.

\begin{tabular}{|c|c|c|}
\hline Groups & Parameter & Signif. \\
\hline \multirow{11}{*}{$\begin{array}{l}\text { 1. } N \text { vs } A K \\
(A \text { vs } B+C)\end{array}$} & Fx-Maxl & $* * *$ \\
\hline & $\mathrm{Fx}-\mathrm{Max} 2$ & $* * *$ \\
\hline & Fx-Max4 & * \\
\hline & Fy-Max 2 & $*$ \\
\hline & Fy-Max4 & $*$ \\
\hline & $\mathrm{Fz}-\mathrm{Max} 2$ & $* * * *$ \\
\hline & $\mathrm{Fz}-\mathrm{Max} 3$ & $*$ \\
\hline & Fz-slope2 & $* *$ \\
\hline & $\mathrm{K}-\mathrm{Max} 2$ & $*$ \\
\hline & $\mathrm{A}-\mathrm{Max} 3$ & $*$ \\
\hline & A-Max4 & $* * *$ \\
\hline 2. $B$ vs $C$ & Fz-Av1 & $* * *$ \\
\hline \multirow{5}{*}{$\begin{array}{l}\text { 3. A vs B } \\
\text { (normal leg) }\end{array}$} & $\mathrm{Fx}-\mathrm{Max} 2$ & $* *$ \\
\hline & Fy-Max 2 & $* * *$ \\
\hline & $\mathrm{F}_{Z}-\mathrm{A} v 1$ & $* * * *$ \\
\hline & Fz-Max2 & $* *$ \\
\hline & A-Max4 & $* *$ \\
\hline \multicolumn{3}{|c|}{$\begin{aligned} \mathrm{N} & =\text { Group } \mathrm{A}: \text { normal subjects } \\
\mathrm{AK} & =\text { above-knee amputees } \\
\mathrm{B} & =\mathrm{AK}, \text { swing leg/prosthesis } \\
\mathrm{C} & =\mathrm{AK}, \text { swing leg/normal leg } \\
* & =\mathrm{p}<0.05 ; * *=\mathrm{p}<0.01 ; * * *=\mathrm{p}<0.001 .\end{aligned}$} \\
\hline
\end{tabular}




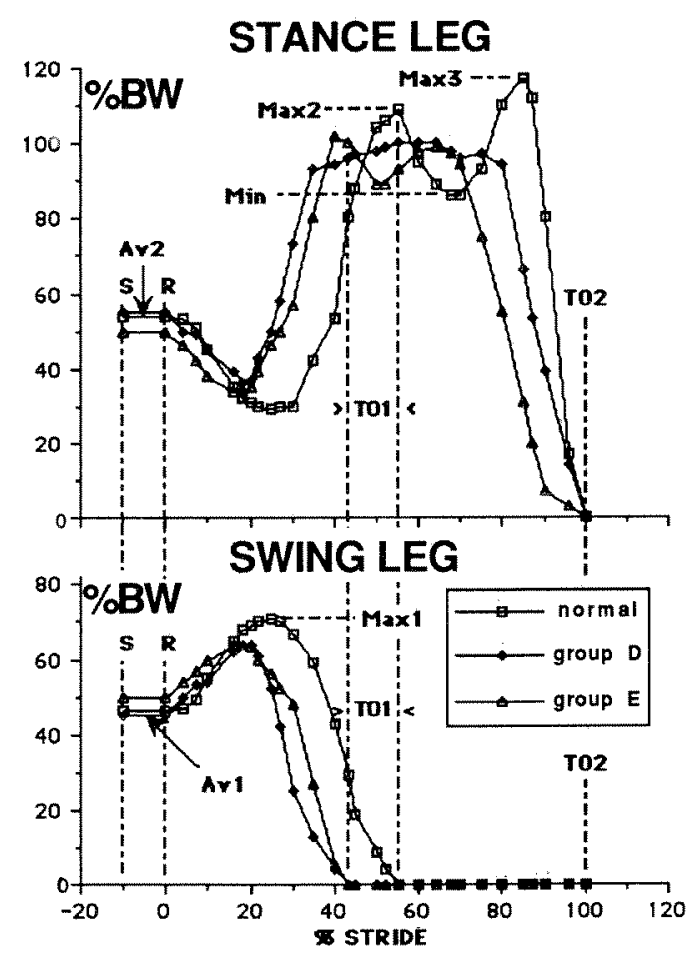

Figure 7.

The vertical force $(\mathrm{Fz})$ in BK amputees and normal subjects.



Figure 8.

The fore-aft force $(\mathrm{Fx})$ in $\mathrm{BK}$ amputees and normal subjects.
STANCE LEG

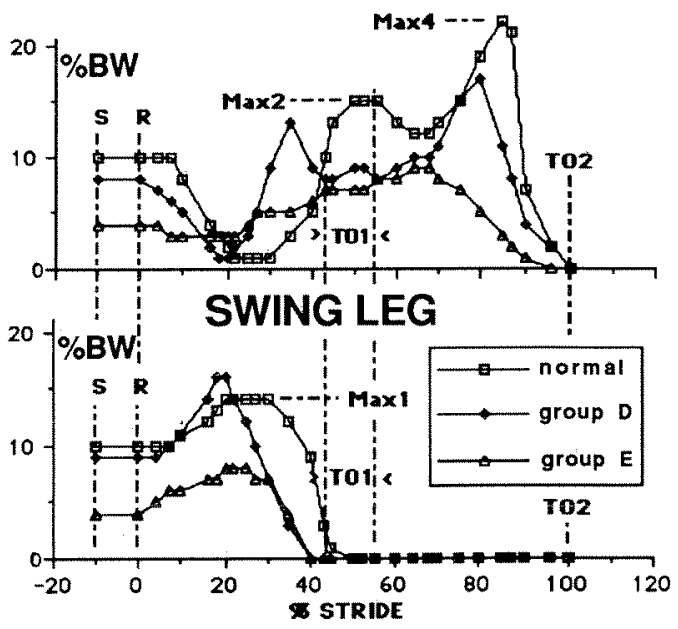

Figure 9.

The mediolateral force (Fy) in BK amputees and normal subjects.

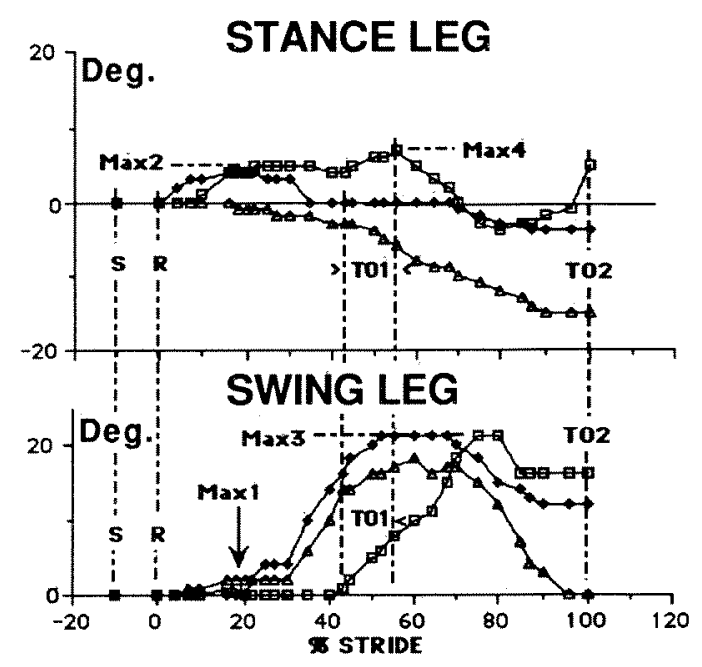

Figure 10.

Flexion-extension of the hips $(\mathrm{H})$ in $\mathrm{BK}$ amputees and normal subjects.

needed for prosthetic assessment will be minimal, noninvasive, relatively simple, and inexpensive. We hope this will help in implementing the system in every orthopedic clinic and prosthetic/orthotic workshop.

Considering the spatial resolution and system inaccuracy described by Whittle (18), the major inaccuracy is inflicted by the small sizes of the various groups and the 
large number of variables involved. In order to have a useful database, the tested groups have to be enlarged significantly; taking into account the various ankle and knee mechanisms, length of stump, age, alignment, etc. This can be done only by a number of centers cooperating on this subject. The amputees in the present study used a variety of knee, ankle, and foot mechanisms, and the prosthesis alignments varied considerably. This situation limits the scope of the analysis to findings common to all $\mathrm{AK}$ or $\mathrm{BK}$ amputees, regardless of their specific prosthesis. Testing groups with defined components and/or alignment will enable an assessment regarding the relative merits of the various variables.

Table 5a.

Summary of results for below-knee (BK) amputees: Forces.

\begin{tabular}{|c|c|c|c|c|c|c|c|c|c|c|c|c|c|c|c|c|c|}
\hline \multirow{2}{*}{$\begin{array}{l}\text { Pt. } \\
\text { Code }\end{array}$} & \multirow{2}{*}{$\begin{array}{c}\text { Amp } \\
\text { type leg }\end{array}$} & \multirow{2}{*}{$\begin{array}{c}\text { Bw } \\
\mathbf{N}\end{array}$} & \multirow{2}{*}{$\begin{array}{l}\text { Swing } \\
\text { leg }\end{array}$} & \multirow{2}{*}{$\begin{array}{l}\mathrm{T1} \\
\mathrm{ms}\end{array}$} & \multirow{2}{*}{$\begin{array}{l}\mathrm{T} 2 \\
\mathrm{~ms}\end{array}$} & \multicolumn{3}{|c|}{$\mathrm{Fx}$} & \multicolumn{4}{|c|}{$\mathrm{Fy}$} & \multicolumn{5}{|c|}{$\mathbf{F z}$} \\
\hline & & & & & & $\begin{array}{l}\text { Max1 } \\
\text { \%BW }\end{array}$ & $\begin{array}{l}\text { Max2 } \\
\% \text { BW }\end{array}$ & $\begin{array}{l}\mathrm{Max4} \\
\% \mathrm{BW}\end{array}$ & $\begin{array}{c}\text { Av1 } \\
\% \mathrm{BW}\end{array}$ & $\begin{array}{l}\text { Max1 } \\
\% B W\end{array}$ & $\begin{array}{l}\text { Max2 } \\
\% B W\end{array}$ & $\begin{array}{l}\text { Max4 } \\
\% B W\end{array}$ & $\begin{array}{c}\text { Av1 } \\
\% \text { BW }\end{array}$ & $\begin{array}{l}\text { Max1 } \\
\% \mathrm{BW}\end{array}$ & $\begin{array}{l}\text { Max2 } \\
\% \mathrm{BW}\end{array}$ & $\underset{\% \text { Min }}{\% \text { BW }}$ & $\begin{array}{l}\text { Max3 } \\
\% \mathrm{BW}\end{array}$ \\
\hline IA8 & BK-R & 650 & $\mathrm{~L}$ & 1000 & 1700 & 6 & 9 & 10 & 2 & 4 & 8 & 8 & 51 & 66 & 102 & 93 & 101 \\
\hline IBI & $B K-L$ & 990 & $\mathrm{~L}$ & 740 & 1530 & 3 & 7 & 10 & 4 & 7 & 9 & 13 & 59 & 83 & 99 & 92 & 96 \\
\hline IB2 & BK-R & 780 & $\mathrm{R}$ & 600 & 1330 & -3 & 5 & 12 & 4 & 8 & 6 & 9 & 47 & 67 & 98 & 96 & 99 \\
\hline IB6 & BK-L & 810 & $\mathrm{~L}$ & 450 & 1160 & -2 & 9 & 13 & 4 & 6 & 5 & 9 & 34 & 46 & 101 & 91 & 98 \\
\hline IB7 & BK-R & 810 & $\mathrm{~L}$ & 690 & 1420 & 2 & 7 & 10 & 4 & 6 & 6 & 9 & 48 & 61 & 102 & 90 & 96 \\
\hline IC6 & BK-L & 740 & $\mathrm{~L}$ & 860 & 1490 & 2 & 6 & 18 & 4 & 6 & 6 & 7 & 45 & 53 & 95 & 86 & 99 \\
\hline ID2 & BK-R & 770 & $\mathrm{~L}$ & 550 & 1240 & 5 & 12 & 14 & 6 & 10 & 8 & 9 & 39 & 55 & 109 & 89 & 100 \\
\hline IF3 & BK-L & 760 & $\mathrm{~L}$ & 590 & 1400 & 2 & 9 & 12 & 3 & 4 & 5 & 8 & 37 & 51 & 96 & 91 & 96 \\
\hline IF7 & BK-R & 590 & $\mathrm{~L}$ & 640 & 1260 & 7 & 10 & 17 & 1 & 7 & 12 & 11 & 56 & 76 & 100 & 90 & 95 \\
\hline $\mathrm{IG} 2$ & BK-R & 980 & $\mathrm{~L}$ & 630 & 1200 & 6 & 13 & 17 & 4 & 7 & 8 & 10 & 47 & 70 & 100 & 90 & 104 \\
\hline \multirow[t]{2}{*}{ Total } & BK: & 788 & - & 675 & 1390 & 3 & 9 & 13 & 4 & 6 & 7 & 10 & 46 & 63 & 100 & 91 & 98 \\
\hline & SD: & 118 & - & 150 & 160 & 3 & 2 & 3 & 1 & 2 & 2 & 2 & 8 & 11 & 4 & 2 & 3 \\
\hline
\end{tabular}

Directions of forces on the legs:

$\mathrm{Fx}_{\mathrm{X}}=$ positive forward

Fy $=$ positive medially

$\mathrm{Fz}=$ positive upwards

Table 5b.

Summary of results for below-knee (BK) amputees: Joint movement.

\begin{tabular}{|c|c|c|c|c|c|c|c|c|c|c|c|c|c|c|c|}
\hline \multirow{2}{*}{$\begin{array}{l}\text { Pt. } \\
\text { Code }\end{array}$} & \multirow{2}{*}{$\begin{array}{c}\text { Amp } \\
\text { type leg }\end{array}$} & \multirow{2}{*}{$\begin{array}{c}\text { Bw } \\
\mathbf{N}\end{array}$} & \multirow{2}{*}{$\begin{array}{c}\text { Age } \\
\mathbf{y}\end{array}$} & \multirow{2}{*}{$\begin{array}{c}\text { Swing } \\
\text { leg }\end{array}$} & \multicolumn{4}{|c|}{ H } & \multicolumn{3}{|c|}{$\mathbf{K}$} & \multicolumn{4}{|c|}{$\mathbf{A}$} \\
\hline & & & & & $\begin{array}{c}\text { Maxl } \\
\text { deg. }\end{array}$ & $\begin{array}{c}\text { Max2 } \\
\text { deg. }\end{array}$ & $\begin{array}{c}\text { Max3 } \\
\text { deg. }\end{array}$ & $\begin{array}{c}\text { Max4 } \\
\text { deg. }\end{array}$ & $\begin{array}{c}\text { Max1 } \\
\text { deg. }\end{array}$ & $\begin{array}{c}\operatorname{Max} 2 \\
\operatorname{deg} .\end{array}$ & $\begin{array}{c}\text { Max3 } \\
\text { deg. }\end{array}$ & $\begin{array}{c}\text { Max1 } \\
\text { deg. }\end{array}$ & $\begin{array}{c}\text { Max2 } \\
\text { deg. }\end{array}$ & $\begin{array}{c}\text { Max3 } \\
\text { deg. }\end{array}$ & $\begin{array}{c}\text { Max4 } \\
\operatorname{deg} .\end{array}$ \\
\hline IA8 & BK-R & 650 & 65 & $\mathrm{~L}$ & 5 & 5 & 18 & 8 & 0 & 0 & 35 & 6 & 0 & -8 & -3 \\
\hline IB1 & BK-L & 990 & 49 & $\mathrm{~L}$ & 1 & -1 & 33 & 4 & -1 & 9 & 40 & -3 & 7 & 11 & -7 \\
\hline $\mathrm{IB} 2$ & BK-R & 780 & 65 & $\mathrm{R}$ & 0 & 4 & 25 & 6 & 0 & 7 & 40 & 6 & 8 & 10 & -8 \\
\hline IB6 & BK-L & 810 & 59 & L & 0 & -3 & 25 & 5 & 1 & 6 & 53 & 2 & 8 & 5 & -11 \\
\hline IB7 & BK-R & 810 & 65 & $\mathrm{~L}$ & 3 & -2 & 22 & 14 & 1 & -7 & 32 & - & 0 & - & - \\
\hline IC6 & BK-L & 740 & 29 & $\mathrm{~L}$ & -2 & 5 & 24 & 2 & -3 & 7 & 44 & -10 & 8 & 12 & -11 \\
\hline ID2 & BK-R & 770 & 62 & $\mathrm{~L}$ & -2 & 6 & 22 & 6 & 6 & 0 & 43 & 17 & 0 & 6 & -1 \\
\hline IF3 & $\mathrm{BK}-\mathrm{L}$ & 760 & 55 & $\mathrm{~L}$ & -1 & 5 & 17 & 3 & 3 & 10 & 30 & 2 & 5 & 11 & -10 \\
\hline IF7 & BK-R & 590 & 19 & $\mathrm{~L}$ & 2 & 3 & 28 & 4 & 5 & -5 & 37 & 10 & -2 & -12 & -6 \\
\hline IG2 & BK-R & 980 & 57 & $\mathrm{~L}$ & 4 & -2 & 30 & 10 & - & -3 & 35 & 7 & 0 & 10 & -7 \\
\hline \multirow[t]{2}{*}{ Total } & BK: & 788 & 53 & - & 2 & 2 & 24 & 6 & 1 & 3 & 39 & - & 4 & 5 & -7 \\
\hline & SD: & 118 & 15 & - & 2 & 3 & 5 & 3 & 3 & 6 & 6 & - & 4 & 8 & 3 \\
\hline
\end{tabular}

Directions of angular movement

$H$ and $K$ are positive in flexion

$A$ is positive in plantarflexion 


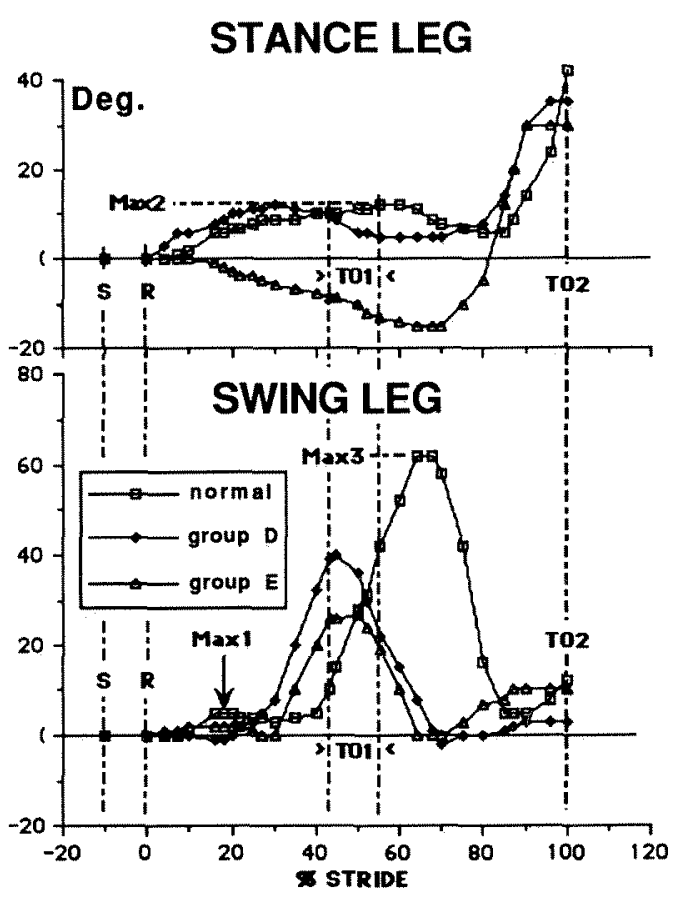

Figure 11.

Flexion-extension of the knees $(\mathrm{K})$ in $\mathrm{BK}$ amputees and normal subjects.

Further parameters (i.e., the impulses and moments of the various forces) have to be investigated in order to achieve a more profound understanding of the complicated period of the initiation of gait.

There are periods of special interest other than the initiation of gait, such as stopping, climbing stairs, etc. During these periods, different parts of the locomotor system are in extensive use, enabling the identification and analysis of various pathologies and misalignments. These periods have to be looked into in the future. A combined analysis based on level walking, IG, and other periods will enable a more accurate diagnosis and fitting of patients and will improve our theoretical knowledge.

\section{ACKNOWLEDGEMENT}

The author would like to acknowledge the kind help and support given by the Oxford Orthopaedic Engineering Centre staff, and especially by Mr. J.D. Harris, Dr. M.W. Whittle, and Dr. A. Turner-Smith.

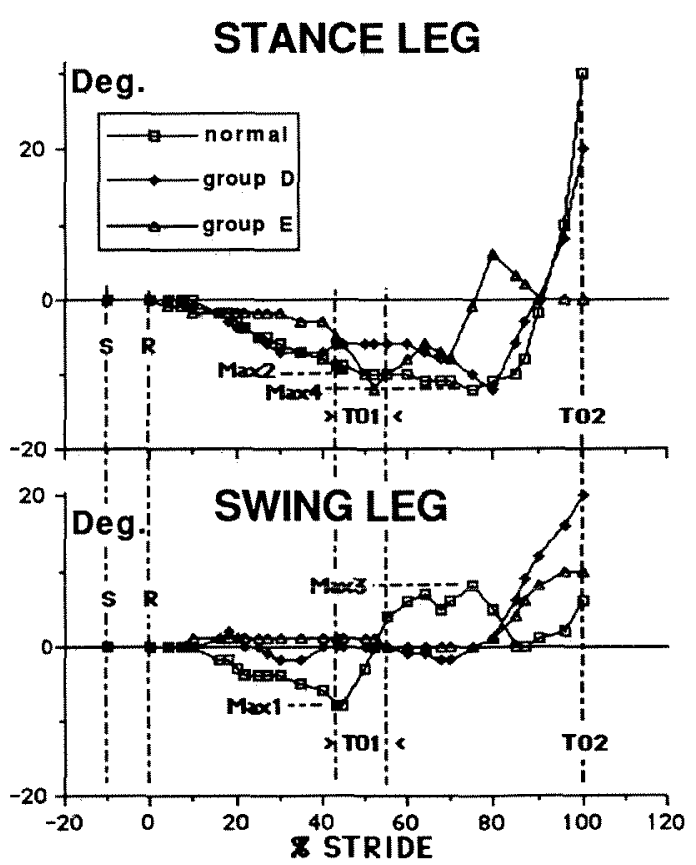

Figure 12.

Dorsiplantar flexion of the ankles (A) in BK amputees and normal subjects.

\section{REFERENCES}

1. Breniere Y, Do MC:: When and how does steady state gait movement induced from upright posture begin? J Biomech 19(2):1035-1040, 1986.

2. Carlsoo S: The initiation of walking. Acta Anat 65:1-9, 1966.

3. Coombes AGA, MacCoughlan J: Development and testing of thermoplastic structural components for modular prostheses. J Int Soc Prosthet Orthot 12(1):19-40, 1988.

4. Dickstein R, Nissan M, Pillar T, Scheer D: Foot ground pressure pattern of standing hemiplegic patients. Major characteristics and patterns of improvement. Phys Ther 64(1):19-23, 1984.

5. Gage JR, Hicks R: Gait analysis in prosthetics. Clin Prosthet Orthot 9(3):17-23, 1985.

6. Herman R, Cook T, Cozzens B, Freedman W: Control of postural reactions in man: The initiation of gait. In: Control of Posture and Locomotion. Stein, Pearson, Smith, Redford (Eds.), New York: Plenum Press, 1973.

7. Kirtley C, Whittle MW, Jefferson RJ: Influence of walking speed on gait parameters. J Biomed Eng 7(4):282-288, 1985. 
Table 6.

Summary of major BK amputees' changes from normal, related to gait timing (upper row).

\begin{tabular}{|c|c|c|c|c|c|c|c|}
\hline group & leg & param & $\mathbf{S}$ & TO1 & & & TO2 \\
\hline \multirow{2}{*}{$\mathrm{D}$} & STANC & $\begin{array}{l}\mathrm{Fx} \\
\mathrm{Fy} \\
\mathrm{Fz} \\
\mathrm{H} \\
\mathrm{K} \\
\mathrm{A}\end{array}$ & $\begin{array}{l}- \\
\text { bigger } \\
- \\
- \\
-\end{array}$ & $\begin{array}{l}\text { smaller } \\
\text { smaller fast loading } \\
\text { less flex }\end{array}$ & $\begin{array}{l}\text { trough missing } \\
\text { reduced flex }\end{array}$ & $\begin{array}{l}\text { smaller } \\
\text { smaller } \\
\text { low peaks } \\
\text { hyperext } \\
\text { extension } \\
\text { smaller pf }\end{array}$ & fast unload \\
\hline & SWING & $\begin{array}{l}\mathrm{Fx} \\
\mathrm{Fy} \\
\mathrm{Fz} \\
\mathrm{H} \\
\mathrm{K} \\
\mathrm{A}\end{array}$ & $\begin{array}{l}- \\
\text { bigger } \\
- \\
- \\
-\end{array}$ & smaller & & $\begin{array}{l}\overline{ } \\
\text { smaller flex } \\
\text { smaller flex }\end{array}$ & \\
\hline \multirow{2}{*}{$E$} & STANC & $\begin{array}{l}\mathrm{Fx} \\
\mathrm{Fy} \\
\mathrm{Fz} \\
\mathrm{H} \\
\mathrm{K} \\
\mathrm{A}\end{array}$ & $\begin{array}{c}- \\
\text { bigger } \\
- \\
- \\
-\end{array}$ & $\begin{array}{l}\text { smaller } \\
\text { smaller fast loading } \\
\text { less flex } \\
\text { less flex } \\
\end{array}$ & $\begin{array}{l}\text { trough missing } \\
\text { ext }\end{array}$ & $\begin{array}{l}\text { smaller } \\
\text { smaller } \\
\text { low peaks } \\
\text { hyperext } \\
\text { smaller pf }\end{array}$ & fast unload \\
\hline & SWING & $\begin{array}{l}\mathrm{Fx} \\
\mathrm{Fy} \\
\mathrm{Fz} \\
\mathrm{H} \\
\mathrm{K} \\
\mathrm{A}\end{array}$ & $\begin{array}{l}- \\
\text { bigger } \\
- \\
- \\
-\end{array}$ & $\begin{array}{l}\text { smaller } \\
- \\
\text { less flex } \\
\end{array}$ & able, depending heavil & $\begin{array}{l}- \\
- \\
\text { smaller flex } \\
\text { smaller flex } \\
\text { ly on make a }\end{array}$ & alignment \\
\hline
\end{tabular}

Group D: prosthesis used as swing leg

Group E: prosthesis used as stance leg

pf $=$ plantarflexion; flex $=$ flexion; ext $=$ extension

8. Mann RA, Hagy JL, White V, Liddell D: The institution of gait. J Bone Joint Surg 61-A(2):232-239, 1979.

9. Murdoch G (Ed.): Prosthetic and Orthotic Practice. London: E. Arnold (Publishers) Ltd., 1970.

10. Nissan M: Analysis of forces in the short below knee stump for the case of PTB leg prosthesis. Masters thesis, Technion, Israel Institute of Technology, Haifa, Israel, 1974.

11. Nissan M: The biomechanics of normal and arthritic knee. PhD diss., University of Strathclyde, Glasgow, Scotland, 1978.

12. Nissan $\mathbf{M}$, Whittle $\mathbf{M W}$ : The initiation of gait in normal subjects. J Biomed Eng 12(2):165-171, 1990.

13. Rigas C: Active plantar-flexion above-knee prosthesis: Concept and preliminary design. Prosthet Orthot Int 9:141-144, 1985.

14. Romick-Allen R, Schultz AB: Biomechanics of reactions to impending falls. $J$ Biomech 21(7):591-600, 1988.

15. Saleh M, Bostock S: An aid to alignment in the belowknee amputee (Abstract). J Bone Joint Surg 70-B(3):497, 1988.

16. Summers GD, Morrison JD, Cockrane GM: Foot loading characteristics of amputees and normal subjects. Prosthet Orthot Int 11:33-39, 1987. 
17. Vittas D, Larsen TK, Jansen EC: Body sway in below knee amputees. Prosthet Orthot Int 10(3):139-141, 1986.

18. Whittle MW: Calibration and performance of a 3-dimensional television system for kinematic analysis. $J$ Biomech 15(3):185-196, 1982.

Table 7.

Statistically significant differences between groups.

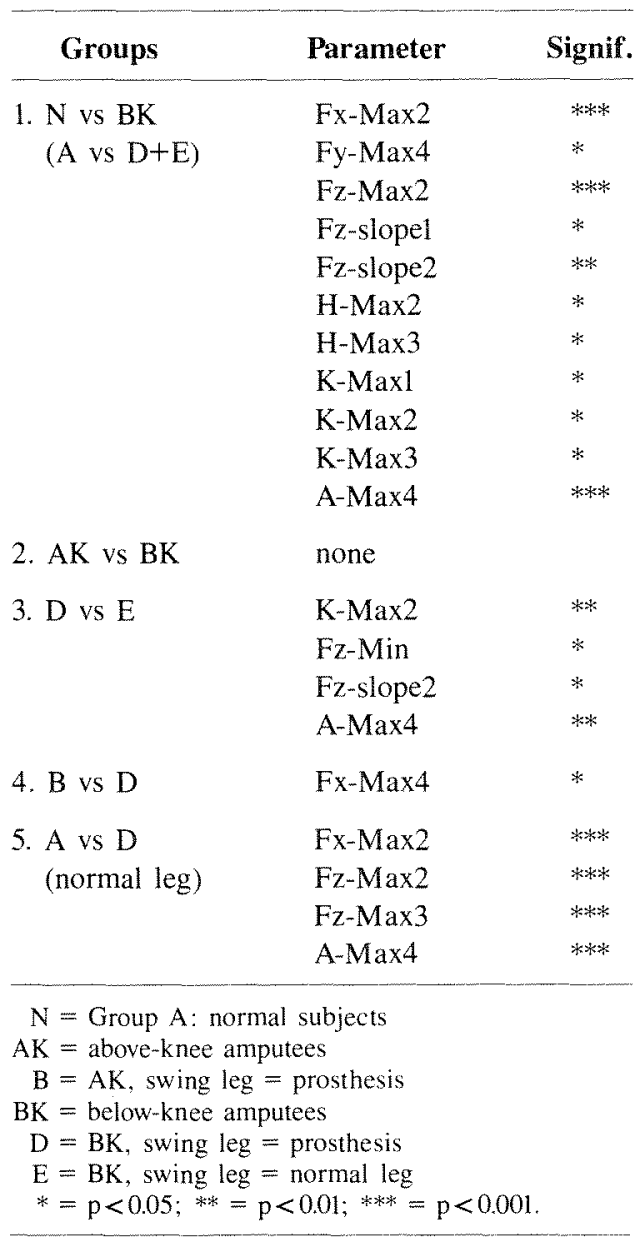

\section{APPENDIX}

The parameters measured in this test and their notation.

Vertical force

Fz-Avl = average force up to $\mathrm{R}$, swing leg, in percent BW FZ-Max1 = maximal force up to TO1, swing leg, in percent BW Fz-Max2 = maximal force up to TO1, stance leg, in percent BW $\mathrm{FZ}-\mathrm{Min}=$ minimal value in the mid-stance trough, in percent $\mathrm{BW}$ Fz-Max3 = maximal force before TO2, stance leg, in percent BW Fz-Slopel = maximal loading slope in stance leg, in $\mathrm{N} / \mathrm{sec}$ Fz-Slope2 = maximal unloading slope towards TO2, in N/sec

\section{Fore-aft force}

Fx-Av1 = average force up to $\mathrm{R}$, swing leg, in percent BW Fx-Maxl = maximal force up to TO1, swing leg, in percent BW $\mathrm{Fx}-\mathrm{Av} 2$ = average force up to $\mathrm{R}$, stance leg, in percent BW FX-Max2 = maximal force up to TO1, stance leg, in percent BW Fx-Max4 = maximal force towards $\mathrm{TO} 2$, in percent $\mathrm{BW}$

\section{Mediolateral force}

Fy-Avl = average force up to R, swing leg, in percent BW Fy-Maxl = maximal force up to TO1, swing leg, in percent BW Fy-Max2 = maximal force up to TO1, stance leg, in percent BW Fy-Max4 = maximal force towards $\mathrm{TO} 2$, in percent $\mathrm{BW}$

\section{Hip, Sagittal plane, in degrees. Positive values are for extension \\ H-Maxl = maximal change up to TO1, swing leg H-Max2 = maximal change up to TO1, stance leg $\mathrm{H}-\mathrm{Max} 3$ = maximal change towards TO2, swing leg H-Max4 = maximal change in mid stance, stance leg}

Knee, Sagittal plane, in degrees. Positive values are for flexion $\mathrm{K}-\mathrm{Max} 1=$ maximal change up to swing-phase flexion, swing leg $\mathrm{K}-\mathrm{Max} 2=$ maximal change up to TO1, stance leg $\mathrm{K}-\mathrm{Max} 3=$ maximal swing phase flexion

Ankle, Sagittal plane, in degrees. Positive values are for plantarflexion

A-Maxl = maximal change up to TO1, swing leg A-Max2 = maximal change up to TO1, stance leg A-Max3 = maximal change in swing phase A-Max $4=$ maximal change in stance phase

Cycle time, in miliseconds

$\mathrm{T} 1=$ from $\mathrm{R}$ to $\mathrm{TO} 1$

$\mathrm{T} 2=$ from $\mathrm{R}$ to $\mathrm{TO} 2$

The maximal values in all cases are the maximal absolute values. 